\title{
COMMON FEMORAL ARTERY DIAMETERS DETERMINED BY DOPPLER ULTRASONOGRAPHY
}

\section{Prună [lon] Irina', Giufu Garmen', Bordei Petru'}

${ }^{1}$ Faculty of Medicine, University "Ovidius" of Constanta

Irina Prună (Ion)

Faculty of Medicine, Univeristy ,Ovidius” of Constanta, Universitatii Alee No. 1, Campus B, Constanta, Romania email:irynaion@yahoo.com phone: +40747031047

\begin{abstract}
Common femoral arteries diameters (left and right) were studied, on a number of 60 cases (26 women and 34 men) with a General Electric - Voluson 730 Expert ultrasonograph. The diameters of the common femoral arteries, left and right, were measured in three points: proximal, middle and inferior, in 60 cases as it follows: 26 cases on women (43,33\%) and 34 cases on men (56,70\%). Regarding the proximal third of the right common femoral artery, the diameter range was found between 6,1 and 8,9mm, in women being between 6,2-7,9mm, and in men between 6,1-8,9mm. The diameter of the middle third had values between $5,8-9,7 \mathrm{~mm}$, in women ranging from 6,1 to $7,8 \mathrm{~mm}$, and in men from 5,8 to 9,7 $\mathrm{mm}$. At the level of the inferior third, the femoral artery had a diameter between $6,8-12,7 \mathrm{~mm}$, in women ranging from 6,5 to 9,8mm, and in men from 6,3 to $12,7 \mathrm{~mm}$. The common left femoral artery, in its proximal third had a diameter with values between 5,7-9,9mm, in women from 6,2 to 8,0 $\mathrm{mm}$, and in men being between 5,7-9,9mm. In the middle third the values were found between 6,1-9,8mm, in women being from 6,6 to 7,9mm, and in men from 6,1 to 9,8mm. Regarding the inferior third, the diameters had values between 7,0-12,5mm, in women ranging from 7,1 to $10,5 \mathrm{~mm}$, and in men, from 6,8 to $12,5 \mathrm{~mm}$.
\end{abstract}

Keywords: common femoral artery, morphometry.

\section{Introduction}

The femoral artery (A. femoralis) directly continues the external iliac artery from the vascular lacunae of the inguinal ligament (femoral ring), stretching until the adductor magnus hiatus, where it will be continued by the popliteal artery $(1,2,3)$. At the level of the femoral ring, the femoral artery is a component of the neurovascular bundle together with the femoral vein, femoral nerve and the deep inguinal lymph nodes (3). The femoral system represents the foremost arterial source of the inferior limb $(3,4)$. The femoral artery is situated in the anteromedial part of the thigh, has an oblique inferomedial and posterior direction, after a line that unites the middle of the inguinal ligament (half the distance between the anterior superior iliac spine and the symphysis pubis) (3), with the posterior margin of the medial femoral condyle $(1,2)$. Under the inguinal ligament, its located in the femoral triangle (Scarpa's triangle), level at which its course is relatively superficial, the femoral axis being linear, heading slightly inferomedial, toward the adductor canal, from where it will travel deeper (5). 


\section{Materials and method}

For the femoral arteries visualization, convex or linear transducers were used, with a frequency between $5-7,5 \mathrm{MHz}$, and a General Electric - Voluson 730 Expert ultrasound. The patients were examined in dorsal decubitus position and in complete rest. We have made a prospective study which included 60 patients with ages between 20 and 60 years, 34 men and 26 women. The measurements were made bilaterally, on both common femoral arteries, in the proximal, middle and inferior or distal third (before the bifurcation), in patients without any declared prior vascular pathology.

\section{Results}

The common femoral artery diameters, left and right, were measured at three levels: proximal, middle and inferior, on a number of 60 cases, 26 of which being females (43,33\%), and 34 males $(56,70 \%)$.

In the proximal third (origin), the right common femoral artery had a diameter between $6,1-8,9 \mathrm{~mm}$, the average being $7,3 \mathrm{~mm}$. In female gender patients, this diameter was found between $6,2-7,9 \mathrm{~mm}$ (with an average of $6,92 \mathrm{~mm}$ ), whereas in male gender, the diameter ranged from 6,1 to $8,9 \mathrm{~mm}$ (with an average of $7,68 \mathrm{~mm}$ ).

Regarding the middle third, the diameter was found between 5,8 and $9,7 \mathrm{~mm}$ (with an average value of $7,48 \mathrm{~mm}$ ), in female patients the values being between $6,1-7,8 \mathrm{~mm}$ (average of $6,97 \mathrm{~mm}$ ), and in male patients between 5,8 $9,7 \mathrm{~mm}$ (average value of $7,98 \mathrm{~mm}$ ).

In the inferior third, we found diameters of the right common femoral artery ranging from 6,8 to $12,7 \mathrm{~mm}$ (with an average value of $8,05 \mathrm{~mm}$ ), in female patients being between 6,5 $9,8 \mathrm{~mm}$ (average value of $8,05 \mathrm{~mm}$ ), and in male patients from 6,3 to $12,7 \mathrm{~mm}$ (average value of $8,97 \mathrm{~mm})$.

Summing up the diameter values from the three right common femoral artery levels, we found that it was ranging from 6,23 to $10,43 \mathrm{~mm}$ (with an average of $8,43 \mathrm{~mm}$ ), in female patients being from 6,26 to $8,50 \mathrm{~mm}$ (average of 7,72mm), and in male patients from 6,10 to $10,43 \mathrm{~mm}$ (with an average value of $8,47 \mathrm{~mm}$ ).

The left common femoral artery had, in the proximal third, a diameter between $5,60-9,90 \mathrm{~mm}$ (with an average of $7,44 \mathrm{~mm}$ ), in female patients between $6,20-8,0 \mathrm{~mm}$ (average of 7,05mm), and in male patients being from 5,70 to $9,90 \mathrm{~mm}$ (with an average of $7,82 \mathrm{~mm}$ ).

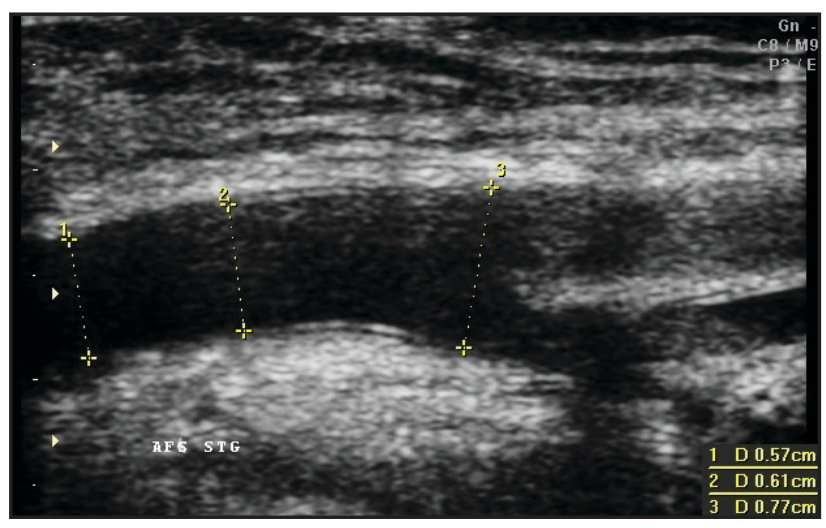

Figure 1-Left common femoral artery diameter: proximal third-5,7mm; middle third-6,1 $1 \mathrm{~mm}$; inferior third $-7,7 \mathrm{~mm}$ (male gender)

In the middle third, the left common femoral artery had diameters ranging from 6,10 to $9,80 \mathrm{~mm}$ (average value of $7,66 \mathrm{~mm}$ ), in female patients from 6,60 to $7,90 \mathrm{~mm}$ (average value of $7,20 \mathrm{~mm}$ ), and in male patients from 6,10 to $9,80 \mathrm{~mm}$ (average value of $8,11 \mathrm{~mm}$ ).

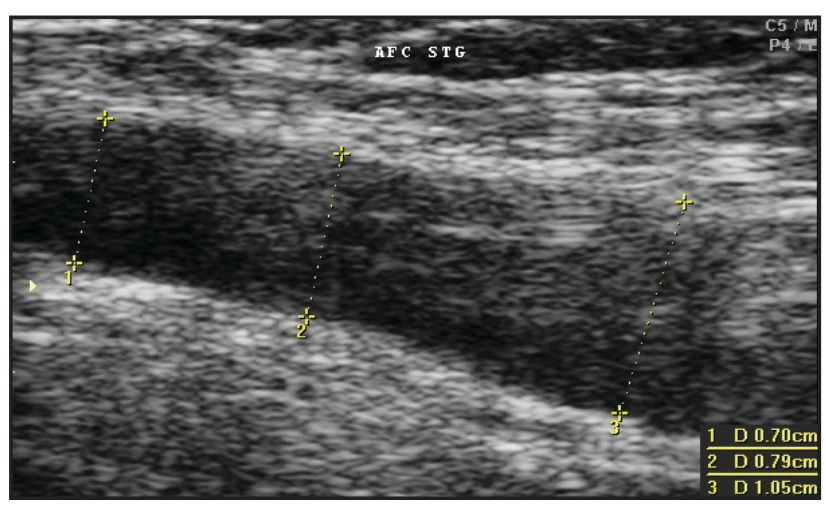

Figure 2 - Left common femoral artery diameter: proximal third-7,0mm; middle third-7,9mm; inferior third $-10,5 \mathrm{~mm}$ (female gender)

The inferior third of the left common femoral artery had diameters with values between 7,0-12,5mm (with an average value of $8,68 \mathrm{~mm}$ ), in female patients being from 7,10 to $10,05 \mathrm{~mm}$ (average value of $8,34 \mathrm{~mm}$ ), and in male patients from 6,80 to $12,50 \mathrm{~mm}$ (average value of $9,02 \mathrm{~mm}$ ). 


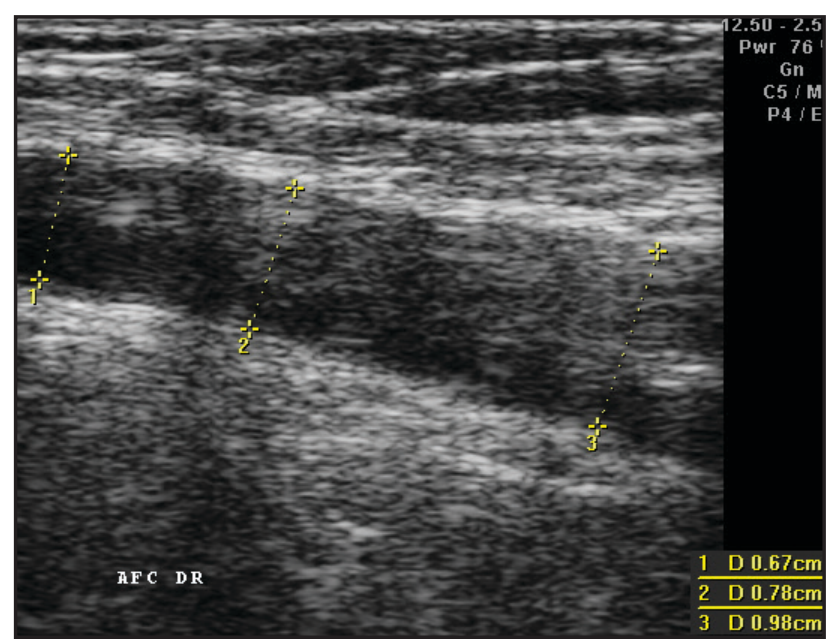

Figure 3-Right common femoral artery diameter: proximal third $-6,7 \mathrm{~mm}$; middle third $-7,8 \mathrm{~mm}$; inferior third-9,8mm (male gender)

Summing up the diameter values obtained in the three measuring points of the left common femoral artery, we found that it was ranging from 6,13 to $10,73 \mathrm{~mm}$ (with an average value of $8,43 \mathrm{~mm}$ ), in the female sex being between $6,63-8,80 \mathrm{~mm}$ (average value of 7,38mm), and in the male sex from 6,20 to $10,73 \mathrm{~mm}$ (an average value of $8,27 \mathrm{~mm}$ ).

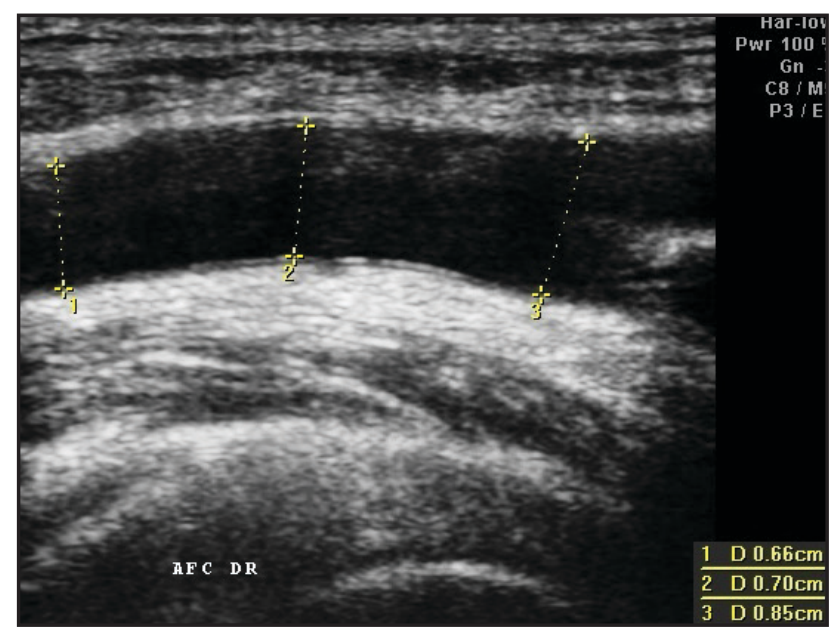

Figure 4 - Right common femoral artery diameter: proximal third-6,6mm; middle third-7,0mm; inferior third $-8,5 \mathrm{~mm}$ (female gender)

\section{Discussions}

Among the international literary references consulted, only (6) gives the diameter at the origin of both common femoral arteries, and its range, without specifying the morphometry regarding gender criteria.
(7) gives the diameter at the origin range, also mentioning its average value, and $(8,9)$ mention the range of the common femoral artery at its origin, without mentioning the patient gender.

Table 1. Common femoral artery diameters

\begin{tabular}{|l|l|}
\hline \multicolumn{1}{|c|}{ Author } & \multicolumn{1}{|c|}{ diam/mm } \\
\hline Kamina & $8-9$ \\
\hline Spector & $3,9-8,9$ \\
\hline Sandgren & male sex: 9,8; female sex: 8,2 \\
\hline Crişan & $8,2+/-014$ \\
\hline & 6,13-10,73 \\
& Proximal third: 5,60-9,90 (avg:7,44); \\
& F: 6,20-8,0 (avg: 7,05); \\
& M: 5,70-9,90 (avg: 7,82); \\
& Middle third: 6,10-9,80 (avg: 7,20); \\
& F: 6.60-7,90 (avg: 7,20); \\
& M: 6,10-9,80 (avg: 8,11); \\
& Inferior third: 7,0-12,5 (avg: 8,68); \\
& F: 7,10-10,50 (avg: 8,34); \\
& M: 6,80-12,50 (avg: 9,02). \\
\hline
\end{tabular}

(5) finds the minimum value of the left common femoral artery diameter at its origin higher than the one found by us with $2,40 \mathrm{~mm}$, and the maximum value, smaller by $0,90 \mathrm{~mm}$; regarding the right common femoral artery, the minimum diameter found by us at its origin was smaller by $2,77 \mathrm{~mm}$, and the maximum value was higher by $1,73 \mathrm{~mm}$.

Regarding the left common femoral artery, the minimum diameter value found by (8) is higher by $2,07 \mathrm{~mm}$ than the one found by us, and the maximum diameter value is smaller than the one we found by $2,39 \mathrm{~mm}$. In (7) the minimum value is smaller than the one we found by $3,23 \mathrm{~mm}$ in the left common femoral artery, and by $3,30 \mathrm{~mm}$ in the right femoral artery; the maximum diameter value found by (7) is smaller by $2,83 \mathrm{~mm}$ in the left femoral artery, and also smaller by $2,53 \mathrm{~mm}$ in the right femoral artery. The average diameter value found by (7) is smaller by $1,83 \mathrm{~mm}$ in the left femoral artery, and by $1,77 \mathrm{~mm}$ in the right femoral artery.

(6) found the average diameter value of the common femoral artery in the female gender higher by $0,48 \mathrm{~mm}$ in the left femoral, and smaller by $0,34 \mathrm{~mm}$ in the right femoral than the values obtained in our study. Regarding male gender, (6) found an average diameter in the left femoral artery, higher by $1,33 \mathrm{~mm}$ than the value 
found by us. The average diameter value in the left common femoral artery found in our study is higher by $0,84 \mathrm{~mm}$ in the proximal third, by $2,0 \mathrm{~mm}$ in the middle third, and by $3,78 \mathrm{~mm}$ in the inferior third.

Making a comparison between the left and right femoral artery diameters, we found that in the proximal third, the left femoral artery diameter was higher than the right femoral artery diameter in 42 cases ( $70 \%$ cases) with differences of $0,1-1,2 \mathrm{~mm}, 18$ female gender cases $(69,23 \%$ of female cases) with differences of $0,2-0,7 \mathrm{~mm}$, and 24 male gender cases $(70,59 \%$ of male cases) with differences of $0,1-1,2 \mathrm{~mm}$. The right common femoral artery had a higher diameter in the proximal third in 18 cases ( $30 \%$ cases) with differences of $0,1-0,7 \mathrm{~mm}, 8$ cases being found in the female cases $(30,77 \%$ of female cases $)$ with differences of $0,1-0,7 \mathrm{~mm}$, and 10 male cases $(19,41 \%$ of male cases) with differences of $0,2-$ $0,7 \mathrm{~mm}$.

In the middle third, in 46 cases $(76,67 \%$ cases), the left common femoral artery diameter was higher by $0,1-0,8 \mathrm{~mm}$ than the right femoral artery, 18 female gender cases $(69,23 \%$ of female cases) with differences of $0,1-0,7 \mathrm{~mm}$, and in 28 male gender cases $(82,35 \%$ of male cases) with differences of $0,1-0,8 \mathrm{~mm}$. In 12 cases $(20 \%$ cases), in the middle third of the artery, the right common femoral artery diameter was higher, 6 female gender cases $(23,08 \%$ of female cases $)$ with diameters higher by $0,1-0,2 \mathrm{~mm}$, and in 6 male gender cases $(17,65 \%$ of male cases $)$, by $0,2-0,7 \mathrm{~mm}$. In 2 cases $(3,33 \%$ cases $)$, both of the female gender $(7,69 \%$ of female cases $)$, the two common femoral arteries, left and right, had the same diameter in the middle third of the artery.

In the inferior third of the common femoral arteries, in 30 cases ( $50 \%$ cases), the left femoral artery diameter was higher by $0,2-1,6 \mathrm{~mm}, 14$ female gender cases $(53,85 \%$ of female cases $)$ with values higher by $0,3-1,6 \mathrm{~mm}$, and 16 male gender cases $(47,60 \%$ of male cases) with differences of $0,2-0,8 \mathrm{~mm}$. In 26 cases ( $43,33 \%$ cases), the right common femoral artery diameter was higher by $0,2-1,1 \mathrm{~mm}, 12$ female cases $(46,15 \%$ of female cases) with values higher by $0,2-0,8 \mathrm{~mm}$, and 14 male cases $(41,18 \%$ of male cases) with values higher by $0,1-1,1 \mathrm{~mm}$. In 4 cases $(6,67 \%$ cases $)$, all of male gender (11,76\% of male cases), both common femoral arteries had the same inferior third diameter.

\section{Conclusions}

The left common femoral artery had frequently a higher diameter value in comparison to the right femoral artery, in $40 \%$ cases in the proximal third ( $38,46 \%$ of female cases and $51,18 \%$ of male cases), $56,67 \%$ cases in the middle third $(45,85 \%$ of female cases and $64,70 \%$ of male cases), and only $6,67 \%$ cases in the inferior third $(7,70 \%$ of female cases and $5,88 \%$ of male cases). Equal diameter values in the two common femoral arteries were found only in the middle third, in the female gender, and in the inferior third, in the male gender. The differences found in the diameter values between the two common femoral arteries, were between $0,1-1,6 \mathrm{~mm}$, being higher than $1 \mathrm{~mm}$ in the poximal third for the left femoral artery, in both common femoral arteries in the inferior third; in the middle third, the differences were smaller than $1 \mathrm{~mm}$.

\section{References}

1. Testut L Artère fémorale et ses branches. In: Traité d'Anatomie humaine, Livre IV. Angéiologie. Ed. G. Doine, Paris, 1928, 226232

2. Delmas A. Arteres du membre inferieure. In: Rouviere $\mathrm{H}$, editor. Anatomie Humaine Tome 3 Systeme nerveux central. Paris: Ed. Masson. p. 443-60, 515-7.

3. Bastide $G$, Lefebvre D. Les arteres de la racine du membre inferieur. Le systeme femoral. In: Chevral JP , editor. Anatomie clinique Les membres. Paris: Ed. SpringerVerlag; 1991. p. 365-7.

4. Standring S. Femoral vessels. In: Grey's anatomy The Anatomical basis of clinical practice. Edinburgh: Ed. Elsevier Churchill Livingstone; 2005. p. 1450-3.

5. Kamina P. Artere femorale. In: Kamina $\mathrm{P}$, editor. Précis d'Anatomie Clinique Tome I Anatomie générale Organogénèse des membres Membre supérieur Membre inférieure. Paris: Ed. Maloine; 2002. p. 47785 
6. Sandgren T, Sonesson B, Ahlgren R, Lanne T. The diameter of the common femoral artery in healthy human: influence of sex, age, and body size. J Vasc Surg. 1999;29(3):503-10

7. Spector KS, Lawson WE. Optimizing safe femoral access during cardiac catheterization. Catheter Cardiovasc Interv. 2001;53(2):20912.

8. Crisan S. Ultrasound examination of the femoral and popliteal arteries. Med Ultrason. 2012;14(1):74-7.

9. $* * * * * * * *$ Terminologia Anatomica

International Anatomical Terminology. Ed.

Thieme, Stuttgart-New York, 1998, 90 